\title{
Factors in Mental Health Problems among Japanese Dialysis Patients Living in Heavily Damaged Prefectures Two Years after the Great East Japan Earthquake
}

\author{
Hidehiro Sugisawa, ${ }^{1}$ Hiroaki Sugisaki, ${ }^{2}$ Seiji Ohira, ${ }^{3}$ Toshio Shinoda, ${ }^{4}$ \\ Yumiko Shimizu, ${ }^{5}$ and Tamaki Kumagai ${ }^{6}$ \\ ${ }^{1}$ Graduate School of Gerontology, J. F. Oberlin University, Machida-shi 194-0294, Japan \\ ${ }^{2}$ Hachioji Azumacho Clinic, Hachioji-shi 192-0082, Japan \\ ${ }^{3}$ Sapporo Kita Clinic, Sapporo-shi 001-0018, Japan \\ ${ }^{4}$ Kawakita General Hospital, Suginami-ku 166-0001, Japan \\ ${ }^{5}$ School of Nursing, Jikei University, Chofu-shi 182-08570, Japan \\ ${ }^{6}$ Faculty of Health Care and Nursing, Juntendo University, Urayasu-shi 279-0023, Japan
}

Correspondence should be addressed to Hidehiro Sugisawa; sugisawa@obirin.ac.jp

Received 29 January 2015; Accepted 15 April 2015

Academic Editor: Kai G. Kahl

Copyright (C) 2015 Hidehiro Sugisawa et al. This is an open access article distributed under the Creative Commons Attribution License, which permits unrestricted use, distribution, and reproduction in any medium, provided the original work is properly cited.

\begin{abstract}
This study examined the prevalence of mental health problems and related factors among dialysis patients living in prefectures that were heavily damaged by the Great East Japan Earthquake. Research was conducted two years following the disaster, and data of 1500 residents of the prefectures were analyzed. This study examined disaster related stressors, gender, socioeconomic status, health problems prior the earthquake, and social support, all of which have been identified as aggravating/mitigating factors in previous research on disaster survivors. We also examined advanced awareness of emergency planning as a dialysis specific factor. Mental health problems after the disaster were categorized into three types: PTSD and depression comorbidity, PTSD only, and depression only. Results indicated that people with comorbidity, PTSD, and depression comprised 7.5\%, 25.0\%, and 2.9\% of the sample, respectively. Not only disaster related stressors but also health problems prior to the disaster had an aggravating direct effect on comorbidity and PTSD. In addition, social support and advanced awareness of disaster planning had a mitigating effect on comorbidity. These results suggest that advanced awareness of disaster planning is a dialysis specific factor that could decrease the occurrence of comorbidity among dialysis patients following a disaster.
\end{abstract}

\section{Introduction}

The earthquake known as the Great East Japan Earthquake occurred on March 11, 2011. The temblor, which was registered at a magnitude of 9.0, triggered a massive tsunami that struck the northeastern coastline, which in turn resulted in a catastrophic failure at the Fukushima Daiichi nuclear power plant, seriously damaging the reactor cooling systems and releasing radioactivity. The compound nature of the disaster - the earthquake, tsunami, and release of radiationdevastated vast areas of northeastern Japan. Many parts of this region have not fully recovered. According to the national police agency, as of November 2012 the death toll from the earthquake and related events stands at 15,883 , with a separate number of 2,651 listed as missing [1].

Effects of natural disasters on certain aspects of mental health in survivors have been identified in most studies reviewed by Norris and Elrod [2]. In Japan, the influence of disaster on survivors' mental health has been examined in relation to previous earthquakes [3-9]. The impact of the Great East Japan Earthquake (also known as the 3/11 earthquake) on mental health has been examined in various groups: people evacuated in shelters [10], young people [1113], and others [14]. Hemodialysis patients are among those 
that have a higher risk of developing mental health problems in the aftermath of natural disasters for the following reasons. First, there is the possibility of disruptions in maintaining regular treatments because many dialysis units might be disabled in the aftermath of a disaster, which can have a harmful impact on the health of hemodialysis patients [15-18]. Second, the available diet in evacuation shelters, which is high in sodium and potassium, could worsen the conditions of patients with chronic renal failure, who are usually on special diets [15, 19]. Third psychological stress, which can have serious health consequences such as triggering heart attacks or strokes, can be more severe in hemodialysis patients than in the general population [20]. However, information on conditions affecting this population following natural disasters is scarce [21]. Hyre et al. [22] reported that $24 \%$ of hemodialysis patients who received treatment in New Orleans during the week before Hurricane Katrina reported symptoms consistent with a diagnosis of PTSD a full year later. In a separate study, Hyre et al. [23] also reported that $46 \%$ of hemodialysis patients in post-Katrina New Orleans reported symptoms consistent with a diagnosis of major depression.

Mental health problems have been shown to be important indicators of related factors such as the deterioration of physical health and greater usage of medical resources [24]. Therefore, this study, conducted approximately two years after the 3/11 earthquake, examined the prevalence of mental health problems and related factors among dialysis patients living in the heavily damaged prefectures.

\section{Methods}

2.1. Analytic Framework. In this study, both exposure to the $3 / 11$ earthquake and life strains after the event were employed as disaster related stressors. This is because life strains after a catastrophic event can be as influential on mental health as the exposure to the disaster itself $[25,26]$. A number of variables have been identified as aggravating/mitigating factors in the mental health of survivors. Many studies have shown that gender, lower social status, and the presence or absence of health problems prior to a disaster are factors related to whether individuals develop serious mental health problems following disasters. Additionally, survivors with higher social support are at reduced risk of developing serious mental health disorders in the future [26]. Moreover, higher awareness of advance emergency planning, specifically, the steps that dialysis patients should take to prepare for a disaster, has been identified as a mitigating factor; the Kidney Community Emergency Response Coalition recommends that dialysis patients be familiar with the emergency renal diet and maintain a list of health problems [27].

The mental health issue most often assessed and observed in research on survivors of natural disasters is Posttraumatic Stress Disorder [2]. A number of previous studies assessing mental health problems of survivors have also reported the prevalence of depression in this population [2]. The present study uses both PTSD and depression in assessing the mental health of survivors and investigated factors related to the comorbidity of PTSD and depression. Tracy et al. [28] suggested that PTSD and depression might be different predictors. Additionally, there are high comorbidity rates between PTSD and depression, and other mental disorders have been reported $[29,30]$, and the presence of depressive disorders in patients with PTSD has been associated with greater functional impairment [31-34]. However, little is known about risk factors involved in comorbidity $[32,34]$.

2.2. Data Sources. Respondent candidates were all members of the Japan Association of Kidney Disease Patients. At the time of the survey they were living in Fukushima, Miyagi, and Iwate, the three prefectures most heavily affected by the earthquake ( $N=4,085)$. According to a survey of all dialysis facilities in Japan conducted by the Japanese Society for Dialysis Therapy [35], the number of dialysis patients living in these three prefectures in December 31, 2012, was $12,679,32.2 \%$ of whom were members of Dialysis Therapy Patient's Association. The questionnaires described below were hand-delivered to members of dialysis facilities. The number of questionnaires returned by mail was 1,845 . However, not all patients that returned the questionnaire were included in the effective sample. As the earthquake occurred in March of 2011 and the survey was conducted in March 2013, patients who began hemodialysis therapy after the earthquake were included as candidate respondents. The questionnaires included a question about the frequency of skipping dialysis treatment due to disruptions caused by the earthquake. Participants $(n=100)$ who indicated that this question was not applicable or did not respond to the question were excluded from the analysis. In addition, the actual number of participants in our analysis was smaller than 1,745 because, as described below, some participants had missing values for variables used in this study.

\subsection{Assessments}

2.3.1. Disaster Related Stressors. Traumatic experiences resulting from the earthquake were measured by a scale that was developed based on scales used in research by Tohyama [36] and other studies [37, 38]. The scale comprised 10 items that evaluated the number of traumatic experiences resulting from the disaster itself (e.g., "suffering injury or burns") that participants may have faced. To quantify the responses, we added up the number of traumatic experiences reported by the participants. The number of traumatic experiences for participants with missing values less than or equal to $20 \%$ of the total traumatic experiences was obtained by calculating individual mean scores for all items other than those with missing values and then calculating the total score by multiplying the individual mean score by 10 . This method has been suggested as a reliable way to handle missing values in surveys using multiple instruments $[39,40]$.

The scale to assess life strains after the earthquake was developed based on the scale used in research by Tohyama [36]. Life strains were defined as "having more difficulties in each life dimension at the time of this survey as compared to one's situation before the disaster." The scale consisted 
of seven life dimension items, assessing variables such as decreasing frequency of contact with friends and neighbors. Participants responded by using the two response choices provided for each item, either "Yes" or "No." Results indicated that, among the 1795 participants in this study, the highest percentage of participants (55.6\%) did not feel any increased difficulties in any of the life dimensions after the disaster, whereas the next highest percentage of participants (11.9\%) felt increased difficulties in only one life dimension. Therefore, life strain was evaluated by whether or not participants felt more difficulty in at least one dimension after the disaster, as compared to before the disaster. Basically, participants who had one and more missing items on this scale were excluded from the analysis. However, even in these participants, respondents who indicated that following the earthquake they felt more difficulty in at least one dimension were used in the analysis.

2.3.2. Other Aggravating/Mitigating and Control Factors. Psychiatric problems prior to the earthquake were retrospectively assessed using the instrument developed by Johannesson et al. [41]. This scale evaluates whether participants suffered from psychiatric problems prior to the earthquake. Traumatic experiences prior to the earthquake were measured using an indicator based on that in research by the Hurricane Katrina Community Advisory Group [42]. Using this indicator, participants were asked if they had experienced any of six different types of traumatic events, such as "psychical, or sexual assault" prior to the 3/11 earthquake. Results indicated that the largest number of traumatic experiences experienced by participants was one (47.6\%) in participants $(n=1,795)$, followed by zero $(39.8 \%)$. Therefore, traumatic experiences prior to the earthquake were evaluated on the basis of whether participants had experienced at least one traumatic event or had no experience of traumatic events. Basically, participants who had one or more missing items on this scale were excluded from the analysis. However, even in these participants, data of those who had experienced at least one traumatic event were used in the analysis.

Activities of daily living (ADL) prior to the earthquake were retrospectively assessed by one item in which participants were asked about their ADL one month prior to the disaster. Response choices comprised five levels, 1 (I could go anywhere by myself without any difficulty) to 5 (I was in bed almost all day) [43] and the total score was calculated. Annual household income during the year prior to the $3 / 11$ earthquake was assessed by measuring the total annual household income. Participants were asked to indicate the approximate total annual income of all household members from all sources of income before tax deductions during the year before the earthquake. There were eight levels of income, from which respondents could choose the most appropriate (e.g., the lowest level was "under 1.2 million yen" and the highest level was "over 10 million yen"), and the midpoint of each category was used for quantification. The midpoint of each category was divided by the square root of the number of people living in the household to adjust for the influence of household size on income. The monetary amount was indicated in units of one million yen.
The two factors that were classified as aggravating/mitigating indicators at the time of this survey were social support and awareness of advance emergency planning. Finally, gender and education were included as sociodemographic factors. The indicator that we termed social support was developed based on questions developed by Americans' Changing Lives [44]. Respondents made assessments regarding three aspects: informational, instrumental, and emotional. The participants were told, "Please indicate the level of support you think that you received from each relationship, such as your spouse, for each aspect of support using the four-point scale." To quantify the response, each response on the scale was assigned a separate value from 1 to 4 . The highest score for resources of social support was used to measure the level of each dimension of social support [45]. Total scores for support were obtained from the sum of the score for each dimension of social support.

Currently, no scale exists to assess advanced awareness of emergency planning among dialysis patients. For the present study, we developed a scale based on recommendations from both the Kidney Community Emergency Response Coalition [46] and a number of dialysis physicians. The scale comprised five items, including items such as the following: "Are there hemodialysis facilities where you can receive dialysis if your current facility is not available due to a disaster?" Participants responded with a "Yes" or "No" to each question. To quantify the responses, we added the number of "Yes" responses by the participants. Missing values on items on the scale were handled in the same manner as in the scale used for exposure to the disaster. To assess education, participants were asked to indicate the highest degree received or most recent educational institution attended. To quantify the responses, the minimum number of years needed to obtain each degree was calculated. In the item for gender, the choices "male" and "female" were assigned the numbers 1 and 0 , respectively. Additionally, age and the length of time an individual had been receiving dialysis treatment were employed as control factors.

2.3.3. Mental Health Problems. The present study employed two indicators to assess mental health problems at the time of the survey: the Impact of Event Scale-Revised (IES-R) as an indicator of PTSD $[47,48]$ and $\mathrm{K} 6$ as an indicator of depression $[49,50]$. Responses to both IES-R and K6 had missing items; however, no methodology exists for handling missing items on these scales. Thus, in the current study, missing values on questionnaires were handled in the same way as on the scale of exposure to the disaster. Participants were categorized into four types (PTSD and depression comorbidity (hereafter comorbidity), PTSD only, depression only, and neither PTSD nor depression) to examine factors related to comorbidity. Categorization into the four types was conducted using a clinical cutoff point for each K6 and PTSD scale to screen for persons with a high possibility of metal health problems (13 for K6 and 25 for ISE-R separately).

2.4. Statistical Analysis. Multinomial logistic regression analysis was used to examine related factors in mental health 
problems. Among the four categories, the classification of neither PTSD nor depression was used as a reference. The effects of aggravating/mitigating factors on mental health problems were examined by entering these factors and control factors as independent variables in the equation. Data of participants without missing values $(89.4 \%)$ for the dependent variables were used in the analysis. The highest percentage of missing values for independent variables was in the indicator of life strains after the earthquake (11.6\%), which was followed by adjusted household income (10.9\%). The percentage of missing values for other independent variables was less than $10 \%$. If we had analyzed only the data of participants without missing values for the independent variables, the effective sample of this study would have been 1,253 because deletions would have reduced the sample size. Therefore, in this study, 1,540 participants with missing values less than or equal to $20 \%$ of the total were included in the analysis through the use of multiple imputation methods. We created 20 data sets that were input to estimate values in items with missing values. The data were analyzed with SPSS version 19.

2.5. Ethical Considerations. This study was conducted according to the guidelines in the Helsinki Declaration. All the procedures of the study were approved by the Research Ethics Board of J. F. Oberlin University. A letter of invitation explaining the content of the study and the questionnaire was handed to each potential participant in this survey. Data collection procedures assured confidentiality by the use of self-administered, anonymous questionnaires. Participation in this study was completely voluntary.

\section{Results}

Table 1 shows the distributions of PTSD, depression, aggravating/mitigating, and control factors. Of the participants, $32.5 \%$ and $10.4 \%$, respectively, showed PTSD and depression. Table 2 shows percentages of different disaster induced traumatic experiences reported by the participants. The highest percentage of participants $(82.2 \%)$ felt fairly or very afraid, which was followed by participants who felt strong anxiety about the safety of their family (46.1\%). Figure 1 shows the distribution of participants with comorbidity (7.5\%), PTSD only $(25.0 \%)$, depression only $(2.9 \%)$, and neither PTSD nor depression $(64.7 \%)$ at the time of the survey. The rate of comorbidity with depression among participants with PTSD was $23.1 \%$ as calculated by the following formula: [comorbidity/(comorbidity + PTSD only) $\times 100$ ]

Table 3 shows the direct effects of aggravating/mitigating factors on mental health problems. There were similar effects of aggravating/mitigating factors on comorbidity and PTSD only. The number of traumatic experiences resulting from the disaster, experiences of life strains after the disaster, gender, health problems prior to the earthquake, and social support had significant impacts on whether participants developed comorbidity or only PTSD. In addition, levels of advanced awareness of emergency planning had significant impact on comorbidity. The number of traumatic experiences due to the disaster, experience of prior (preearthquake) depression,

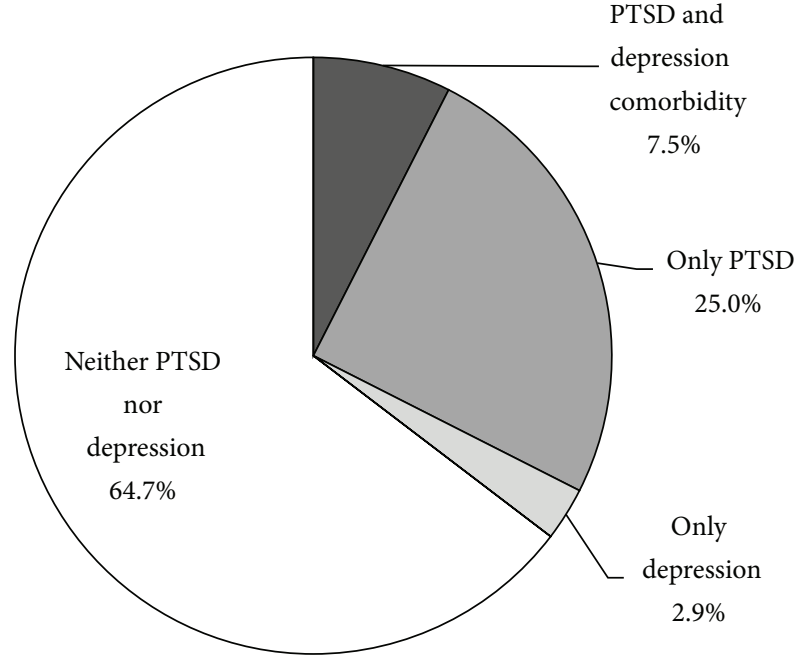

FIGURE 1: Prevalence of PTSD and depression at the time of the survey.

and prior difficulties of ADL had significant impacts on depression only.

\section{Discussion}

It is rather difficult to compare the above findings with prevalence of PTSD reported in previous studies, as methodologies and referenced sources of population from previous studies were different from those used here [51]. However, according to a systematic review by Neria et al. [52], studies of survivors of natural disasters overall report PTSD prevalence ranging from $3.7 \%$ to $60 \%$ in the first one to two years after an event, with most studies reporting prevalence estimates in the lower half of this range. In addition, estimates of higher prevalence of PTSD have been reported in specific groups such as clinical samples and populations in areas heavily affected by a disaster. As this study included participants who did not directly experience the earthquake and/or tsunami, it should be noted that prevalence of PTSD in participants with exposure to disaster was 32.5\%. Hyre et al. [22] reported that $91.8 \%$ of hemodialysis patients in their sample were evacuated after Hurricane Katrina and $42.2 \%$ of these individuals reported symptoms consistent with PTSD or partial PTSD one year following the disaster. These results suggest that hemodialysis patients not only are vulnerable to the immediate physical effects of disaster but also may experience longer term mental health issues; this is despite the fact that the period during which these factors occur, that is, the disaster and the aftermath, is seen as being short term [26]. As K6 is a global indicator, comparison with prevalence of depression in a reference group is needed to evaluate whether prevalence of depression among the dialysis patient sample is high or low. Kuriyama et al. [53] reported that the prevalence of depression measured using K6 among a population of persons living in Japan aged 40 and over was $6.7 \%$. Prevalence of depression among the dialysis patients in our sample after the earthquake was $10.4 \%$, twice that of 
TABLE 1: Descriptive statistics of variables under investigation ${ }^{\mathrm{a}}$.

\begin{tabular}{|c|c|c|}
\hline Variable & & \\
\hline Prevalence rate of PTSD & $(\%)$ & 32.5 \\
\hline Prevalence rate of depression & $(\%)$ & 10.4 \\
\hline Number of traumatic experiences resulting from the earthquake & Mean (SD) & $2.217(1.474)$ \\
\hline Rate of experiencing life strains after the earthquake & $(\%)$ & 36.1 \\
\hline \multirow{2}{*}{ Gender } & Male (\%) & 42.7 \\
\hline & Female (\%) & 57.3 \\
\hline Education (number of years) & Mean (SD) & $12.042(2.159)$ \\
\hline Income (in units of one million yen) & Mean (SD) & $2.027(1.413)$ \\
\hline Rate of experiencing depression prior to the earthquake & $(\%)$ & 17.0 \\
\hline Rate of traumatic experiences prior to the earthquake & $(\%)$ & 61.6 \\
\hline Levels of disability of ADL (activity of daily living) prior to the disaster & Mean (SD) & $2.148(1.176)$ \\
\hline Levels of awareness of advanced planning & Mean (SD) & $2.695(1.421)$ \\
\hline Social support & Mean (SD) & $10.769(1.909)$ \\
\hline Age (years) & Mean (SD) & $64.688(10.670)$ \\
\hline Period undergoing dialysis (number of years) & Mean (SD) & $11.420(8.280)$ \\
\hline
\end{tabular}

${ }^{a}$ Numbers were calculated by using 20 data sets for inputting estimated values instead of missing values $N=1,540$.

TABLE 2: Percentage of different traumatic experiences caused by the disaster $^{\mathrm{a}}$

\begin{tabular}{lc}
\hline Kind & $(\%)$ \\
\hline Feeling fairly or very afraid & 82.2 \\
Strong anxieties about family safety & 46.1 \\
Finding shelter & 35.7 \\
Partial or complete destruction of home & 19.1 \\
Suffering from a permanent physical injury & 14.3 \\
Helping to rescue victims of the disaster & 9.0 \\
Seeing dead or seriously injured people & 7.3 \\
Death of a family member & 3.3 \\
Suffering from injury or burns & 2.9 \\
Injury or permanent physical damage to a family member & 1.4 \\
\hline a A database for inputting estimated values for missing values was used $(n=$ \\
1,540). Missing values were input to the scale indicating the number of \\
traumatic experiences caused by the disaster. However, missing values for \\
each type of traumatic experience caused by the disaster were not input. \\
$\begin{array}{l}\text { Percentages of the types of disaster were calculated by excluding each case } \\
\text { with missing values. }\end{array}$
\end{tabular}

the general population. However, it has been widely claimed that depression is the most common mental health problem among dialysis patients; this is not only because dialysis patients may have experienced multiple difficulties at home and work, for example, fatigue and sexual dysfunction, but also due to multiple stressors such as dietary constraints and dependency upon treatment [54].

Previous studies have reported that rates of comorbid depression among participants with PTSD were over 40\% [30, $34,55]$. The rate of comorbid depression among participants with PTSD in this sample (23.1\%) was lower than that found in other studies of disaster survivors. As the current study is the first to examine comorbidity following a disaster in dialysis patients, this finding may not be conclusive. However, if these results prove to be valid, differences in each risk factor for PTSD and depression after a disaster among dialysis patients could be wider than in the risk factors among the general population. As depression among dialysis patients is often related to dialysis specific stressors, such as role changes at home and in the workplace [54], it is possible that the factors related to depression differ largely from other disaster related stressors that cause PTSD. Factors related to comorbidity and PTSD only in our sample of dialysis patients are similar to factors related to mental health problems in disaster survivors found in previous research [2]. Tracy et al. [28] point to certain stressors during and following a natural disaster that play a central role in PTSD and also cite postevent nontraumatic stressors that are associated with risk of depression. In this study, disaster related stressors had a lower impact on depression than on comorbidity and PTSD. Dialysis specific causes of depression among patients may have had an influence on our results.

While awareness of advance emergency planning is important in reducing deaths among dialysis patients in the event of a natural disaster [21], in empirical research only Hyre et al. [23] have demonstrated that a lack of evacuation plan awareness was related to poor psychosocial health following a disaster. The results in this study provide support for the effectiveness of advance emergency planning and awareness of measures that can be taken in preventing mental health problems among dialysis patients.

There are some limitations in the present research. First, assessments of changes in depression were not possible as preearthquake data from this region were not available. Second, assessments of recovery from the acute phase immediately following the earthquake were not possible as the study interviews were conducted only once, two years after the events of 3/11. Third, it is difficult to examine the causal linkage of these factors to an appearance of mental health problems as several factors prior to the earthquake were collected through a retrospective survey. Finally, a low response rate (here $45.2 \%$ ) is thought to provide an underestimation 
TABLE 3: Direct effects of aggravating/mitigating factors on mental health problems ${ }^{\mathrm{a}}$.

\begin{tabular}{|c|c|c|c|}
\hline & PTSD and depression ${ }^{\mathrm{b}}$ & PTSD only ${ }^{\mathrm{b}}$ & Depression only ${ }^{\mathrm{b}}$ \\
\hline & Odds ratio ${ }^{c}(95 \% \mathrm{CI})$ & Odds ratio $^{c}(95 \% \mathrm{CI})$ & Odds ratio $^{c}(95 \% \mathrm{CI})$ \\
\hline The number of traumatic experiences caused by disaster & $1.494(1.288-1.733)^{* * *}$ & $1.425(1.293-1.572)^{* * *}$ & $1.299(1.037-1.626)^{*}$ \\
\hline Experience of life stressors after the earthquake & $3.858(2.307-6.452)^{* * *}$ & $2.096(1.560-2.816)^{* * *}$ & $1.151(0.566-2.339)$ \\
\hline Gender $($ male $=1$, female $=0)$ & $0.655(0.420-1.021)$ & $0.735(0.562-0.963)^{*}$ & $1.473(0.764-2.840)$ \\
\hline Education & $0.916(0.820-1.024)$ & $0.922(0.863-0.986)^{*}$ & $1.052(0.907-1.221)$ \\
\hline Income & $0.934(0.781-1.117)$ & $0.912(0.820-1.015)$ & $0.810(0.623-1.051)$ \\
\hline $\begin{array}{l}\text { Experience of depression } \\
\text { prior to the earthquake }\end{array}$ & $4.971(3.062-8.069)^{* * *}$ & $2.058(1.454-2.912)^{* * *}$ & $5.032(2.606-9.717)^{* * *}$ \\
\hline $\begin{array}{l}\text { Experience of trauma } \\
\text { prior to the earthquake }\end{array}$ & $1.520(0.950-2.432)$ & $1.517(1.151-2.000)^{* *}$ & $0.527(0.282-0.986)^{*}$ \\
\hline Levels of disability in activities of daily living prior to the earthquake & $1.579(1.313-1.899)^{* * *}$ & $1.200(1.066-1.351)^{* *}$ & $1.330(1.026-1.724)^{*}$ \\
\hline Levels of awareness of disaster planning & $0.751(0.634-0.891)^{* *}$ & $1.049(0.954-1.153)$ & $0.810(0.642-1.020)$ \\
\hline Social support & $0.862(0.776-0.959)^{* *}$ & $0.927(0.864-0.994)^{*}$ & $0.963(0.825-1.124)$ \\
\hline Age & $1.022(1.000-1.045)$ & $1.021(1.007-1.035)^{* *}$ & $0.969(0.942-0.998)^{*}$ \\
\hline Period of taking dialysis & $1.011(0.983-1.038)$ & $0.997(0.981-1.013)$ & $0.998(0.960-1.037)$ \\
\hline
\end{tabular}

of the rates of PTSD or depression, as patients with more serious mental health problems have a higher possibility of not responding to this type of survey. Although these limitations need to be noted, the present research has several important features that should be noted: (1) this is the second quantitative study to examine the effects of a natural disaster on a population of dialysis patients, the first being the previously mentioned study following Hurricane Katrina; (2) this study uncovered related factors in comorbidity, a very important mental health issue following a disaster; and (3) previous studies on survivors of earthquakes and other natural disasters have been conducted with selective samples that were not representative of the affected population [56]. While this study had a selective sample, the sample was obtained from members of patient groups, which comprised one-third of all patients living in the affected prefectures. Evidence based on convenience sampling or snowballing methods tends to show substantially higher rates of PTSD and other mental disorders than seen in representative groups recruited using random sampling methods [57]. Evidence from this study has smaller bias of prevalence of mental health problems than that found in other researches using convenience sampling.

\section{Conclusion}

People with comorbidity, PTSD only, and depression only comprised $7.5 \%, 25.0 \%, 2.9 \%$ of the sample, respectively. Not only disaster related stressors but also health problems prior to the disaster had an aggravating direct effect on comorbidity and PTSD. In addition, social support and advanced awareness of disaster planning had a mitigating effect on comorbidity. Results of this study suggest that the awareness of disaster planning in advance could mitigate the occurrence of comorbidity. Disaster related stressors had a weaker impact on depression than on comorbidity and PTSD. Dialysis specific stressors may have played a large part in depression among patients after the disaster and mental and physical health prior to the disaster.

\section{Conflict of Interests}

All the authors declare no competing interests.

\section{Acknowledgments}

The authors acknowledge the help from the board members of Iwate, Miyagi, and Fukushima of Japan Association of Kidney Disease Patients. This study was supported by the research fund for fiscal 2013 of the Japanese Association of Dialysis Physicians.

\section{References}

[1] National Police Agency of Japan Emergency Disaster Countermeasures Headquarters, Damage Situation and Police Countermeasures, 2014, http://www.npa.go.jp/archive/keibi/biki/higaijokyo.pdf.

[2] F. H. Norris and C. L. Elrod, "Psychological consequences of disaster," in Methods for Disaster Mental Health, F. H. Norris, S. Galea, M. J. Friedman, and P. J. Watson, Eds., pp. 20-42, The Guilford Press, New York, NY, USA, 2006.

[3] T. Fujimori and K. Fujimori, "Mental health of victims of 1993 Hokkaido Nanseioki Earthquake," Psychiatry Diagnosis, vol. 7, pp. 65-76, 1993.

[4] M. Tanaka and O. Takagi, "A study of the victims in the temporary housing built outside of the stricken disaster area of 
the Great Hanshin-Awaji Earthquake I: the impact on physical and mental health of the people in the temporary housing a year after the Earthquake," The Japanese Journal of Experimental Social Psychology, vol. 37, no. 1, pp. 76-84, 1997 (Japanese).

[5] T. Fujimori, "Prolong mental health problems due to natural disaster: a study of Hokkaido Nanseioki Earthquake victims," The Japanese Journal of Personality, vol. 7, no. 1, pp. 11-21, 1998 (Japanese).

[6] S. Fukuda, K. Morimoto, K. Mure, and S. Maruyama, "Posttraumatic stress and change in lifestyle among the Hanshin-Awaji earthquake victims," Preventive Medicine, vol. 29, no. 3, pp. 147151, 1999.

[7] S. Fukuda, K. Morimoto, K. Mure, and S. Maruyama, "Effect of the Hanshin-Awaji earthquake on posttraumatic stress, lifestyle changes, and cortisol levels of victims," Archives of Environmental Health, vol. 55, no. 2, pp. 121-125, 2000.

[8] S.-I. Toyabe, T. Shioiri, H. Kuwabara et al., "Impaired psychological recovery in the elderly after the Niigata-Chuetsu Earthquake in Japan: a population-based study," BMC Public Health, vol. 6, article 230, 2006.

[9] S.-I. Toyabe, T. Shioiri, K. Kobayashi et al., "Factor structure of the General Health Questionnaire (GHQ-12) in subjects who had suffered from the 2004 Niigata-Chuetsu Earthquake in Japan: a community-based study," BMC Public Health, vol. 7, article 175, 2007.

[10] J. Tayama, T. Ichikawa, K. Eguchi, T. Yamamoto, and S. Shirabe, "Tsunami damage and its impact on mental health" Psychosomatics, vol. 53, no. 2, pp. 196-197, 2012.

[11] Y. Kotozaki and R. Kawashima, "Effects of the Higashi-Nihon earthquake: posttraumatic stress, psychological changes, and cortisol levels of survivors," PloS one, vol. 7, no. 4, 2012.

[12] M. Usami, Y. Iwadare, M. Kodaira et al., "Relationships between traumatic symptoms and environmental damage conditions among children 8 months after the 2011 Japan Earthquake and tsunami," PLoS ONE, vol. 7, no. 11, Article ID e50721, 2012.

[13] T. Takeda, M. Tadakawa, S. Koga, S. Nagase, and N. Yaegashi, "Premenstrual symptoms and posttraumatic stress disorder in Japanese high school students 9 months after the great eastJapan earthquake," Tohoku Journal of Experimental Medicine, vol. 230, no. 3, pp. 151-154, 2013.

[14] M. Fushimi, "Posttraumatic stress in professional firefighters in Japan: rescue efforts after the Great East Japan earthquake (Higashi Nihon Dai-Shinsai)," Prehospital and Disaster Medicine, vol. 27, no. 5, pp. 416-418, 2012.

[15] A. Inui, H. Inoue, M. Uemoto, M. Kasuga, and H. Taniguchi, "Kobe earthquake and the patients on hemodialysis," Nephron, vol. 74, no. 4, article 733, 1996.

[16] S. J. Hwang, K. H. Shu, J. D. Lain, and W. C. Yang, "Renal replacement therapy at the time of the Taiwan Chi-Chi earthquake," Nephrology Dialysis Transplantation, vol. 16, supplement 5, pp. 78-82, 2001.

[17] M. S. Sever, E. Erek, R. Vanholder et al., "Features of chronic hemodialysis practice after the Marmara Earthquake," Journal of the American Society of Nephrology, vol. 15, no. 4, pp. 10711076, 2004.

[18] A. H. Anderson, A. J. Cohen, N. G. Kutner, J. B. Kopp, P. L. Kimmel, and P. Muntner, "Missed dialysis sessions and hospitalization in hemodialysis patients after Hurricane Katrina," Kidney International, vol. 75, no. 11, pp. 1202-1208, 2009.

[19] S. Ochi, V. Murray, and S. Hodgson, "The Great East Japan Earthquake disaster: a compilation of published literature on health needs and relief activities, March 2011-September 2012," PLOS Currents Disasters, vol. 5, 2013.

[20] N. Haga, J. Hata, K. Ishibashi, M. Nomiya, N. Takahashi, and Y. Kojima, "Blood pressure in hemodialysis patients after Great East Japan earthquake in Fukushima: the effect of tsunami and nuclear power accident," Journal of Hypertension, vol. 31, no. 8, pp. 1724-1726, 2013.

[21] R. C. Vanholder, W. A. van Biesen, and M. S. Sever, "Hurricane Katrina and chronic dialysis patients: better tidings than originally feared?" Kidney International, vol. 76, no. 7, pp. 687-689, 2009.

[22] A. D. Hyre, A. J. Cohen, N. Kutner, A. B. Alper, and P. Muntner, "Prevalence and predictors of posttraumatic stress disorder among hemodialysis patients following Hurricane Katrina," American Journal of Kidney Diseases, vol. 50, no. 4, pp. 585-593, 2007.

[23] A. D. Hyre, A. J. Cohen, N. Kutner et al., "Psychosocial status of hemodialysis patients one year after Hurricane Katrina," American Journal of the Medical Sciences, vol. 336, no. 2, pp. 9498, 2008.

[24] D. Edmondson, C. Gamboa, A. Cohen et al., "Association of posttraumatic stress disorder and depression with all-cause and cardiovascular disease mortality and hospitalization among hurricane katrina survivors with end-stage renal disease," American Journal of Public Health, vol. 103, no. 4, pp. e130-e137, 2013.

[25] C. R. Brewin, B. Andrews, and J. D. Valentine, "Meta-analysis of risk factors for posttraumatic stress disorder in trauma-exposed adults," Journal of Consulting and Clinical Psychology, vol. 68, no. 5, pp. 748-766, 2000.

[26] F. H. Norris, M. J. Friedman, P. J. Watson, C. M. Byrne, E. Diaz, and K. Kaniasty, "60,000 disaster victims speak: part I. An empirical review of the empirical literature, 1981-2001," Psychiatry, vol. 65, no. 3, pp. 207-239, 2002.

[27] J. B. Kopp, L. K. Ball, A. Cohen et al., "Kidney patient care in disasters: emergency planning for patients and dialysis facilities," Clinical Journal of the American Society of Nephrology, vol. 2, no. 4, pp. 825-838, 2007.

[28] M. Tracy, F. H. Norris, and S. Galea, "Differences in the determinants of posttraumatic stress disorder and depression after a mass traumatic event," Depression and Anxiety, vol. 28, no. 8, pp. 666-675, 2011.

[29] R. C. Kessler, A. Sonnega, E. Bromet, M. Hughes, and C. B. Nelson, "Posttraumatic stress disorder in the national comorbidity survey," Archives of General Psychiatry, vol. 52, no. 12, pp. 10481060, 1995.

[30] M.-L. Meewisse, M. Olff, R. Kleber, N. J. Kitchiner, and B. P. R. Gersons, "The course of mental health disorders after a disaster: predictors and comorbidity," Journal of Traumatic Stress, vol. 24, no. 4, pp. 405-413, 2011.

[31] E. Önder, Ü. Tural, T. Aker, C. Kiliç, and S. Erdoğan, "Prevalence of psychiatric disorders three years after the 1999 earthquake in Turkey: Marmara Earthquake Survey (MES)," Social Psychiatry and Psychiatric Epidemiology, vol. 41, no. 11, pp. 868-874, 2006.

[32] E. B. Foa, D. J. Stein, and A. C. McFarlane, "Symptomatology and psychopathology of mental health problems after disaster," Journal of Clinical Psychiatry, vol. 67, supplement 2, pp. 15-25, 2006.

[33] R. Shah, A. Shah, and P. Links, "Post-traumatic stress disorder and depression comorbidity: severity across different populations," Neuropsychiatry, vol. 2, no. 6, pp. 521-529, 2012. 
[34] Ü. Tural, E. Önder, and T. Aker, "Effect of depression on recovery from PTSD," Community Mental Health Journal, vol. 48, no. 2, pp. 161-166, 2012.

[35] The Committee of Statistical Survey-the Japanese Society for Dialysis Therapy, An Overview of Regular Dialysis Treatment in Japan, 2012, http://docs.jsdt.or.jp/overview/pdf2013/p008.pdf.

[36] T. Tohyama, "Stressors associated with the subsequent mental conditions of the outpatients exposed to the Great Hanshin Earthquake," Journal of Nara Medical Association, vol. 49, no. 5, pp. 295-311, 1998 (Japanese).

[37] A. Roussos, A. K. Goenjian, A. M. Steinberg et al., "Posttraumatic stress and depressive reactions among children and adolescents after the 1999 earthquake in Ano Liosia, Greece," The American Journal of Psychiatry, vol. 162, no. 3, pp. 530-537, 2005.

[38] S. Galea, M. Tracy, F. Norris, and S. F. Coffey, "Financial and social circumstances and the incidence and course of PTSD in Mississippi during the first two years after Hurricane Katrina," Journal of Traumatic Stress, vol. 21, no. 4, pp. 357-368, 2008.

[39] F. M. Shrive, H. Stuart, H. Quan, and W. A. Ghali, "Dealing with missing data in a multi-question depression scale: a comparison of imputation methods," BMC Medical Research Methodology, vol. 6 , article $57,2006$.

[40] C. Bono, L. D. Ried, C. Kimberlin, and B. Vogel, "Missing data on the Center for Epidemiologic Studies Depression Scale: a comparison of 4 imputation techniques," Research in Social and Administrative Pharmacy, vol. 3, no. 1, pp. 1-27, 2007.

[41] K. B. Johannesson, T. Lundin, T. Fröjd, C. M. Hultman, and P.-O. Michel, "Tsunami-exposed tourist survivors: signs of recovery in a 3-year perspective," Journal of Nervous \& Mental Disease, vol. 199, no. 3, pp. 162-169, 2011.

[42] Hurricane Katrina Community Advisory Group, Baseline Interview for the Hurricane Katrina Community Advisory Group, Hurricane Katrina Community Advisory Group, 2006, http:// www.hurricanekatrina.med.harvard.edu/pdf/baseline_overview_1-06.pdf.

[43] Department of Social Welfare. Tokyo Metropolitan Institute of Gerontology, Ed., Family Caregiving for the Elderly and Service Needs for Caregiving, Koseikan, Tokyo, Japan, 1996, (Japanese).

[44] J. S. House, Americans' Changing Lives: Waves I and II, 1986 and 1989. ICPSR Version, Survey Research Center, University of Michigan, Ann Arbor, Mich, USA, 1997.

[45] H. Sugisawa, J. Liang, and X. Liu, "Social networks, social support, and mortality among older people in Japan," Journals of Gerontology, vol. 49, no. 1, pp. S3-S13, 1994.

[46] E. M. Ginexi, K. Weihs, S. J. Simmens, and D. R. Hoyt, "Natural disaster and depression: a prospective investigation of reactions to the 1993 Midwest Floods," American Journal of Community Psychology, vol. 28, no. 4, pp. 495-518, 2000.

[47] D. S. Weiss and C. R. Marmer, "The impact of event scalerevised," in Assessing Psychological Trauma and PTSD, J. P. Wilson and T. M. Keane, Eds., pp. 399-411, Guilford Press, New York, NY, USA, 1997.

[48] N. Asukai, H. Kato, N. Kawamura et al., "Reliability and validity of the Japanese-language version of the impact of event scalerevised (IES-R-J): four studies of different traumatic events," Journal of Nervous and Mental Disease, vol. 190, no. 3, pp. 175$182,2002$.

[49] R. C. Kessler, G. Andrews, L. J. Colpe et al., "Short screening scales to monitor population prevalences and trends in nonspecific psychological distress," Psychological Medicine, vol. 32, no. 6, pp. 959-976, 2002.
[50] T. A. Furukawa, N. Kawakami, M. Saitoh et al., "The performance of the Japanese version of the K6 and K10 in the World Mental Health Survey Japan," International Journal of Methods in Psychiatric Research, vol. 17, no. 3, pp. 152-158, 2008.

[51] P. Udomratn, "Mental health and the psychosocial consequences of natural disasters in Asia," International Review of Psychiatry, vol. 20, no. 5, pp. 441-444, 2008.

[52] Y. Neria, A. Nandi, and S. Galea, "Post-traumatic stress disorder following disasters: a systematic review," Psychological Medicine, vol. 38, no. 4, pp. 467-480, 2008.

[53] S. Kuriyama, N. Nakaya, K. Ohmori-Matsuda et al., "Factors associated with psychological distress in a community-dwelling Japanese population: the Ohsaki Cohort 2006 study," Journal of Epidemiology, vol. 19, no. 6, pp. 294-302, 2009.

[54] J. Chilcot, D. Wellsted, M. Da Silva-Gane, and K. Farrington, "Depression on dialysis," Nephron-Clinical Practice, vol. 108, no. 4, pp. c256-c264, 2008.

[55] M. Başoğlu, C. Kiliç, E. Şalcioğlu, and M. Livanou, "Prevalence of posttraumatic stress disorder and comorbid depression in earthquake survivors in Turkey: an epidemiological study," Journal of Traumatic Stress, vol. 17, no. 2, pp. 133-141, 2004.

[56] S. Priebe, F. Marchi, L. Bini, M. Flego, A. Costa, and G. Galeazzi, "Mental disorders, psychological symptoms and quality of life 8 years after an earthquake: findings from a community sample in Italy," Social Psychiatry and Psychiatric Epidemiology, vol. 46, no. 7, pp. 615-621, 2011.

[57] M. Fazel, J. Wheeler, and J. Danesh, "Prevalence of serious mental disorder in 7000 refugees resettled in western countries: a systematic review," The Lancet, vol. 365, no. 9467, pp. 1309$1314,2005$. 


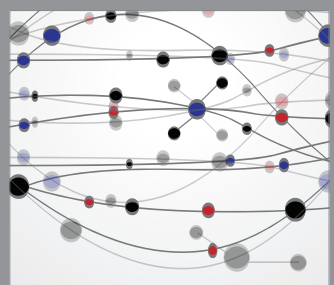

The Scientific World Journal
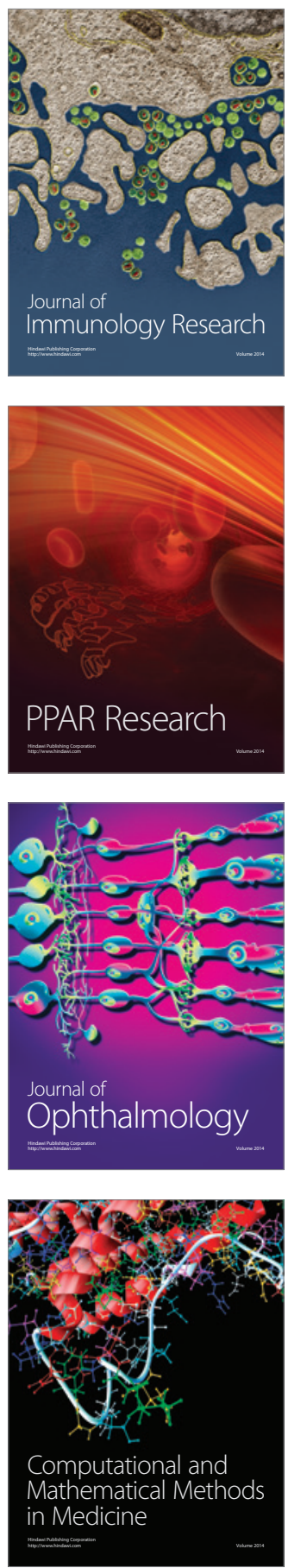

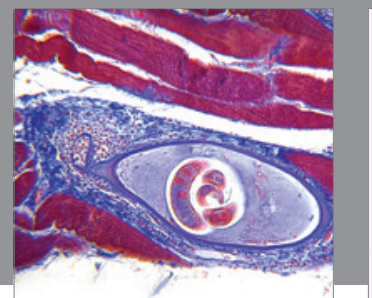

Gastroenterology

Research and Practice
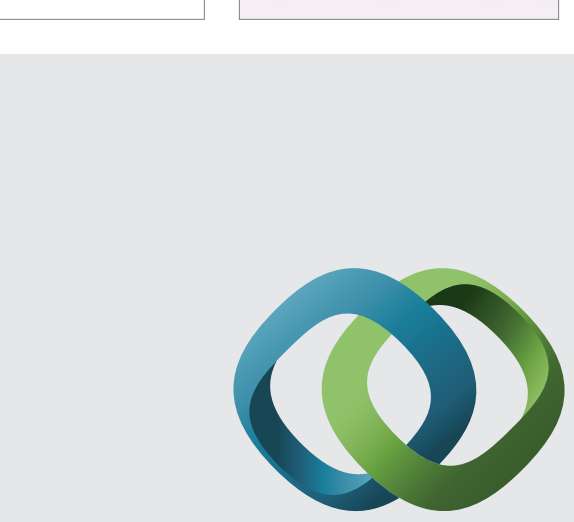

\section{Hindawi}

Submit your manuscripts at

http://www.hindawi.com
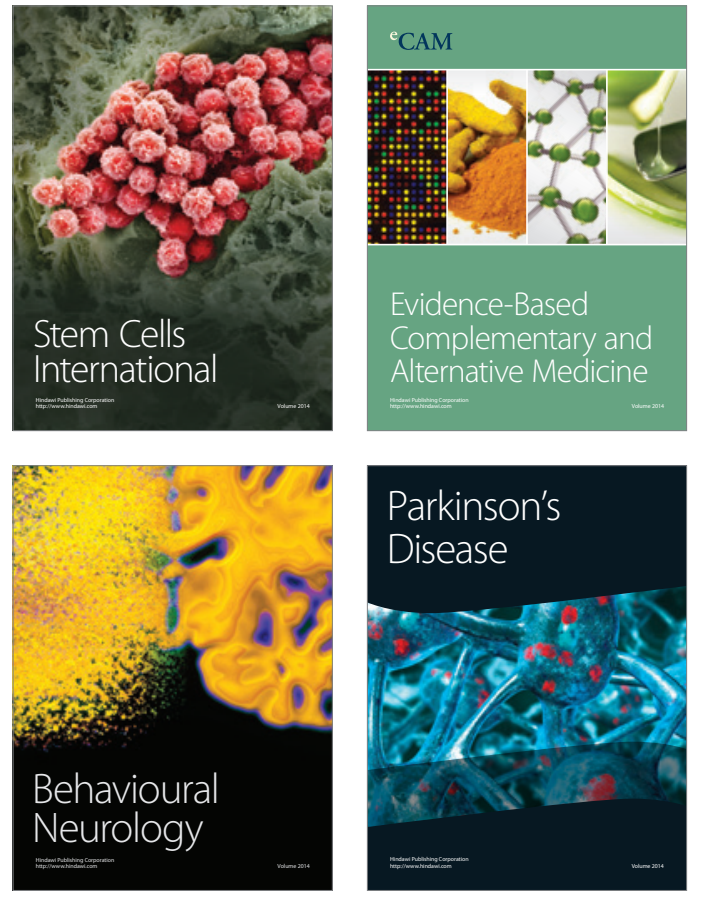
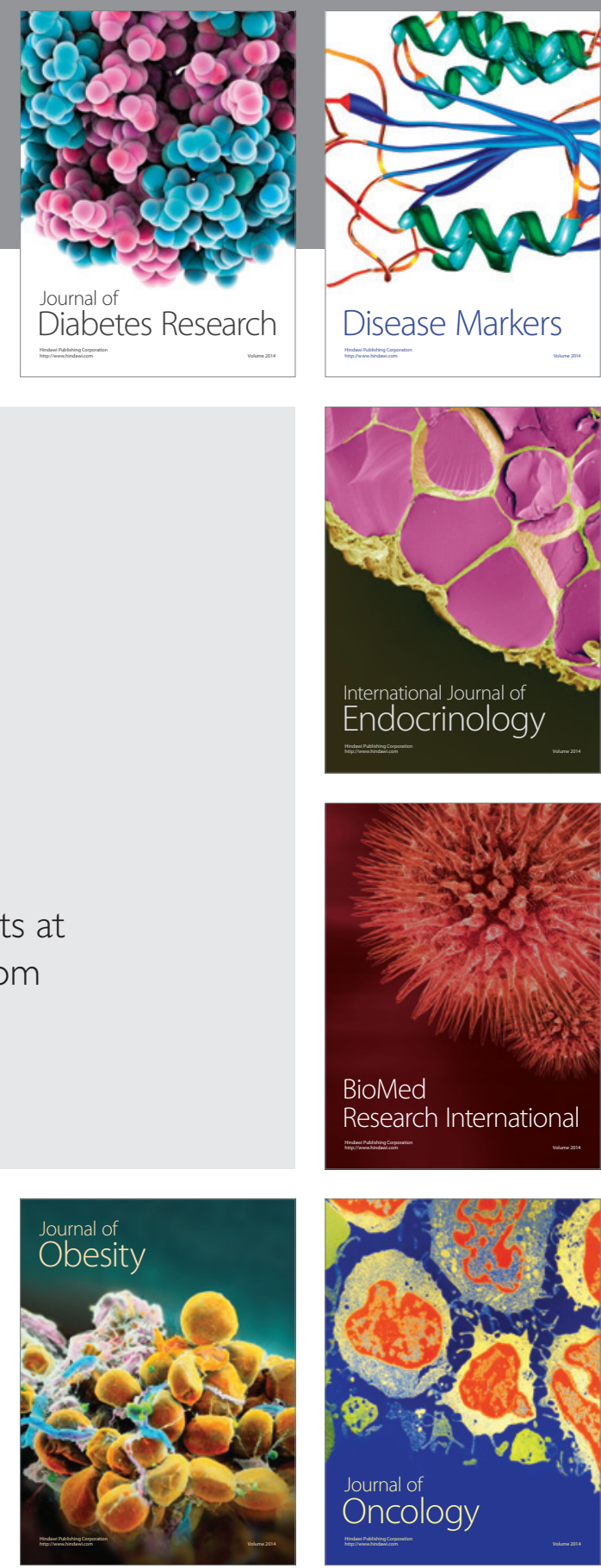

Disease Markers
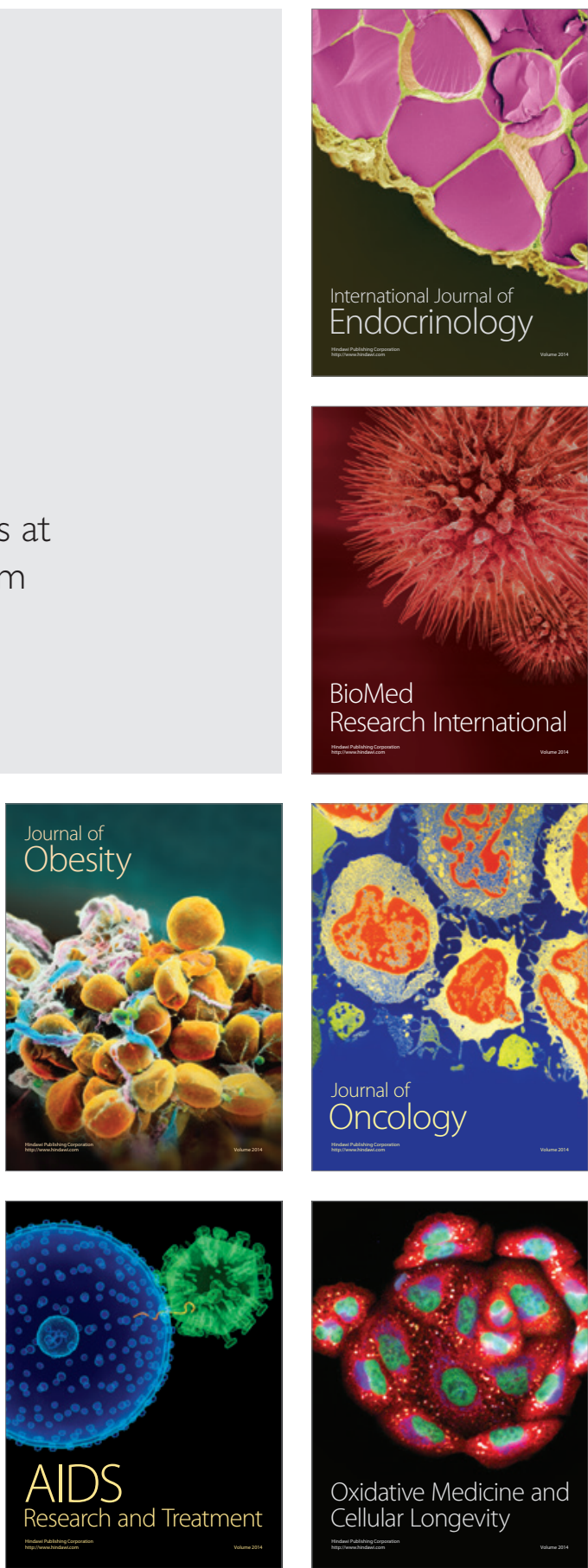